\title{
Making Adult Safeguarding Personal
}

\author{
M.Redley ${ }^{1}$, S. Jennings ${ }^{1}$, A.J. Holland ${ }^{1,2,3}$ I.C.H. Clare ${ }^{1,2,3}$
}

1 Cambridge Intellectual \& Developmental Disabilities Research Group, Department of Psychiatry

2 NIHR Collaboration for Applied Health Research \& Care (CLAHRC) East of England at Cambridgeshire \& Peterborough NHS Foundation Trust

3 Cambridgeshire \& Peterborough NHS Foundation Trust

\section{Acknowledgements}

We are grateful to all our interviewees, without whom the project could not have taken place. We are also grateful to the County Council's Safeguarding Adults Board for their support for the project and for their comments on a previous version of this report, and to Suzie Tall for administrative support. SJ's contribution was funded by The Health Foundation. Support for MR, AJH and ICHC was provided initially by the NIHR CLAHRC for Cambridgeshire \& Peterborough), and subsequently by The Health Foundation (MR) and the NIHR CLAHRC East of England (AJH and ICHC). The views expressed are those of the authors and not necessarily those of the NHS, the NIHR or the Department of Health.

Adult Safeguarding, the process by which local authorities are charged with protecting adults with care and support needs from abuse, and which became part of the Care Act 2014, is a wide-ranging and complex task (Mandelstam, 2013). It covers a range of harms: including theft, fraud, neglect, ill-treatment, assault, rape, and death that may take place within healthcare, social care and community settings. In addition, adult safeguarding interfaces with numerous other statutory and policy frameworks. These define, for example, the responsibilities of the National Health Service; regulate the provision of social care; sets out the support that must be given to vulnerable victims and witnesses in the criminal justice system; and describe the process that must be followed when making decisions on behalf of someone who lacks the capacity make one or more health, welfare, or financial decisions for themselves. This paper, however, is not directly concerned with either the legislation or the policies and procedures that define the safeguarding responsibilities of English local authorities. Rather, it is focused on the efforts that staff in these local authorities should be making to deliver outcomes that are valued by those they seek to protect. As such, the service evaluation reported here considers whether, and to what extent, Adult Safeguarding Leads (ASLs) are involving the service users they seek to protect in decisions about protective measures. The relevance of this issue lies in the concern that local authorities, in acting to safeguard an adult from one type of abuse, inadvertently act in a manner that might abuse that service user's dignity, 
happiness and human rights (Social Care Institute for Excellence, 2007 , Department of Health, 2009, Munby, 2013).

\section{Background}

Formal efforts to ensure that adult safeguarding services were involving those they sought to protect in decisions about protective measures can be traced back to 2009 when the Local Government Association, the Association of Directors of Adult Social Services (ADASS) and the Social Care Institute for Excellence (SCIE) began its Making Safeguarding Personal (MSP) initiative. This initiative started with a literature review identifying a dearth of evidence as to 'what works' in adult safeguarding. No one knew, with any accuracy, the extent to which adult safeguarding delivered outcomes that its service users valued or how professional practice might best be evaluated (Ogilvie and Williams, 2009). This startling revelation was followed by a 'tool kit' of ideas designed with the intention of personalising adult protection (Ogilvie and Williams, 2010) and explicitly aligning it with the rest of adult care and support (Department of Health, 2011, Department of Health, 2007). The ideas contained in the tool kit emphasised the importance of service user empowerment and involvement: offering suggestions for: promoting control and choice through personalised information and advice, building service users' confidence and selfesteem through peer and professional support, and promoting the value of advocacy in the adult safeguarding process. The tool kit subsequently became the basis for a number of practical projects in the years 2012-13 and 2013-14, in which participating local authorities - five in the first year, and fifty-three in the second - sought to transform what was perceived as a professionally-led process into one that was person-centred (Lawson et al., 2014). The projects saw participating local authorities pioneering a variety of novel ways of working that would first ascertain the experiences and desired outcomes for people using safeguarding adults services, and then ensure that the subsequent safeguarding process focussed on delivering those outcomes. Some local authorities, however, such as the one involved in the study reported here, postponed the introduction of such new ways of working because it sought, first, to evaluate how it was responding to the MSP initiative by examining (a) the efforts of Adult Safeguarding Leads, generic advocates, and Independent Mental Capacity Advocates (IMCAs) to involve service users in decisions about protective measures; and (b) whether its Adult Safeguarding service was delivering outcomes valued by its users. 


\section{Method}

The study, which was carried out during 2013, in partnership with a local University, was based in one County Council, serving a total population of c. 500,000 in the East of England. Semi-structured interviews were conducted with ten Adult Safeguarding Leads (ASLs) working in five different community-based teams across the County: (i) intake and assessment; (ii) planned care; (iii) learning disabilities; (iv) older people; and (v) people with physical and/or sensory disabilities. In addition, interviews were conducted with four advocates: two generic advocates and two IMCAs.

Unfortunately - and perhaps because we could not approach them directly but only through other agencies - we were only able to recruit and interview three users of the Adult Safeguarding service. The interviews with the ASLs and the IMCAs addressed the following issues: (i) whether adult safeguarding was a person-centred process; (ii) the involvement of advocates in adult safeguarding; (iii) how service users were supported to take part in the safeguarding process, and (iv) and what they regarded as a good outcome. At the insistence of the Council, who were concerned about the possibility of causing distress, the interviews with the three service users were far less structured. Nevertheless, we sought to ascertain from the service users (i) their understanding of adult safeguarding, (ii) their experiences of the process; and (iii) whether they felt their circumstances had changed for the better following referral to the service. All interviews were conducted face-to-face, and were 20 to 60 minutes' duration, and were audio-recorded. The interviewer adopted a challenging stance towards the professional participants in order to develop a lively discussion (Holstein and Gubrium, 1997). The interviews were transcribed verbatim and examined for content, with emergent themes identified and coded (Cicourel, 1964). The codes and the subsequent analysis were refined and validated through meetings of the research team. Since the aim of this paper is to document the practicalities of adult safeguarding, rather than to analyse the subjective experiences of respondents, no quotations from the interview data are presented.

The research governance managers at the University, and the County Council, judged the study to be a 'service evaluation', as defined by the National Research Ethics Service (NRES). Consequently, permission for it to proceed was granted without the need for a formal ethical review by NRES. Nevertheless, since the study involved vulnerable adults, albeit no one who was thought to lack capacity to give or withhold consent to participation, it was submitted to the University's Psychology Research Ethics Committee. Following formal review, it was approved.

\section{Findings}


Our findings, divided into three parts, report on the interviews: a) with the ASLs; b) with advocates; and c) with service users.

\section{a) The perspectives of Adult Safeguarding Leads}

The interviews with the ASLs suggested that the main factor contributing to a personcentred approach to the involvement of an alleged victim in adult safeguarding procedures was not that person's decision-making capacity. Nor was it features of the abuse such as its nature and/or severity. Rather, it was the type of setting in which the abuse was thought to have taken place. ASLs distinguished two different kinds of what are, formally, both community settings: a 'residential' setting (such as a care home providing long-term accommodation and support) and a 'community' setting (a person's own home or that of a family member).

This distinction between 'residential' and 'community' settings seemed crucial to ASLs' understanding of the service and their relationships with their service users. With respect to residential settings, the ASLs offered a number of reasons why the experiences of individual service users might not match the highest expectations of a person-centred approach. Of primary importance, the cases generally related to the provision and delivery of the care by the provider rather than to the lifestyles and/or choices of service users. Where it appeared that one person was experiencing abuse as a consequence of poor quality care, it was thought likely that other residents were also affected, even where no further referrals to the Adult Safeguarding service had been made. In such cases, it was reported, the task of the service became a matter of ensuring that service improvements took place through identifying, and taking steps to address, any poor practice. Initially, these steps normally involved changes to users' care plans, more thorough record-keeping, and ensuring that staff received appropriate training and/or supervision. Much of this, we were told, could be accomplished with very limited involvement of the men and women living in the care home or other type of residential placement: it did not depend on users' awareness of poor care, their decision-making capacity, or the safeguarding process and any subsequent protective measures. As a consequence, those ASLs involved in cases of abuse occurring in residential settings did not see adult safeguarding as a personcentred process. Of far more importance, in these cases, we were told, were the anxieties of family members who sought reassurance about the safety and well-being of their relatives. We were also told that safeguarding in residential settings investigating alerts and identifying protective measures - was fairly straightforward since what is considered good quality care in these settings is clearly discernible and uncontroversial. This was not the case in other kinds of community settings. 
In contrast, addressing alleged abuse that took place in a person's own home or a family member's home was reported to be very complex. First, there were some situations, such as family members refusing to allow the service to meet privately with alleged victims, which simply did not occur in residential settings. Our data do not allow us to say whether, or how, these difficulties were resolved. Secondly, in 'community' settings, the views of possible victims were much more salient. While the importance given to service users' wishes should have made it easier to adopt a person-centred approach, ASLs reported that, in reality, it did not. Typically, service users wanted the abuse to end, but they did not wish for any formal investigations of the nature and/or severity of what had allegedly taken place, let alone investigations that might involve the police and perhaps lead to legal proceedings. ASLs described the difficulties of reconciling these views: all too often, when inquiries commenced, service users refused further involvement with the Adult Safeguarding service, or felt upset when they believed that the safeguarding process had compromised their relationships with perpetrators. It was reported that alleged victims often sought to remain on cordial terms with their perpetrators because they feared that the involvement of the criminal justice system, or even of the County Council, might lead to an escalation of their abuse. We were told that, where alleged victims were judged to have capacity to make the relevant decisions for themselves, their refusals to engage were accepted. However, ASLs reported that they never ruled out the possibility of further involvement at a later date, should a service user change his or her mind. Indeed, we were told, individuals often had multiple referrals and ASLs described how discouraging they found it to see the same service users appearing repeatedly.

There was only one situation in which, according to ASLs, the service user's expressed wishes might be over-ruled: when both the alleged victim and perpetrator were considered to be vulnerable as a result of their age and/or learning disability. In these situations, gaining access and implementing protective measures was described as more straightforward. The reasons were uncertain but there was a suggestion that the 'status' of both the alleged victim and the perpetrator enabled ASLs to feel more confident about intervening.

Surprisingly, the ASLs we spoke to had little experience of working with people who, while not living in residential accommodation, might lack capacity to make one or more of the decisions relevant to Adult Safeguarding. When asked about such cases, 
their responses were technically correct (for example, making reference to the Mental Capacity Act 2005 and acknowledging that decisions made on a service user's behalf had to be in that person's 'best interests') but were rather general; no case examples were provided.

\section{Involving service users and their families}

All the ASLs thought that the involvement of service users and their families was very important, regardless of the setting of the alleged abuse. However, the activities that were reported as examples of such involvement, such as learning about the experiences and feelings of the alleged victim, ascertaining his or her wishes about possible further actions, and providing information as the case developed, did not always appear to be applied with the vigour and rigour needed to meet the ideals of the MSP initiative. Moreover, what we were told suggested that there were strict limits to even modest goals for user involvement. It was reported, for example, that service users rarely attended strategy meetings. This seemed to reflect, in part, the belief that service users would not wish to be present when their experiences were discussed. In addition, however, there were occasions on which, ASLs reported, service users' attendance was judged to be inappropriate: for example, where they appeared to be physically frail and/or were judged to lack capacity to make one or more decisions about possible further action. Similarly, where a strategy meeting might involve more than one victim, such as would very often be the case where allegations were made about abuse in a residential setting, there was general agreement that involving service users was complicated by the risk that confidential information about others in the same placement might become known. The few ASLs who reported involving victims reported that the service users' presence kept the meeting person-focussed, but we were not able to establish whether or how this might affect outcomes. Where alleged victims were involved in strategy meetings, it was reported that they were most likely to be younger people, living in their own or their family's home and with physical and/or sensory disabilities, as the capacity of these adults was thought to be unchallengeable.

In addition, there were some concerns about involving family members, at least in strategy meetings. It was reported that members of service users' families might be disruptive through being argumentative or focussed on their own agenda as opposed to that of the meeting. There were also concerns that the presence of family members might, if there were more than one alleged victim, compromise service users' confidentiality. 


\section{The role of IMCAs and other advocates}

It seemed that the ASL participants we interviewed were committed to the idea of a 'professionals' meeting', which might be attended by advocates, but not by service users and/or their families. All ten ASLs demonstrated an awareness of the IMCA service and the role of specialist advocates in supporting service users who were judged to lack capacity to make one or more of the relevant decisions for themselves. IMCA services were viewed very positively. First, they were praised for their professionalism; in contrast with family members, it was reported that the advocates could be relied on to respect confidential information and behave appropriately in meetings, and yet remain independent. Secondly, it was believed that, because IMCAs had fewer demands on their time, they were more likely than ASLs to be able to establish the wishes, feelings and beliefs of service users. While there was a general awareness that alleged victims who did not lack capacity could be represented or supported by a general advocate, only two of the ten ASLs had experience of working with them. For these two participants, a general advocate's involvement was seen exclusively in terms of supporting the alleged victim to attend a strategy meeting; there was no sense that this advocate might support a service user to express his or her own views.

\section{The meaning of a 'good' outcome}

When we asked directly about how the experiences and views of alleged victims contributed to outcomes, ASLs responded only that their service users always wanted an end to what was happening to them. When pressed further, we were told that alleged victims were often unaware that their experiences constituted abuse and/or knew little about the safeguarding process and/or were fearful of all but the most limited involvement of Adult Safeguarding because of the possible impact not only on their relationship/s with the alleged perpetrator/s but also, more broadly, on their lives. Family members, in contrast, were presented as much more interested in outcomes, seeking reassurance that their relative was safe, and that the perpetrator/s were, in some way, 'dealt with'.

Among the ASLs themselves, there were differing views about the meaning of a 'good' outcome. For those working mainly with abuse in residential settings, there was agreement that the goal of their involvement was to bring about improvements in the quality of care and support provided to their service user and others living in the same placement. In contrast, among ASLs working in service users in their own 
homes or those of family members, there was uncertainty. Was it an ASL's

withdrawal from a safeguarding investigation because a victim stated strongly that $\mathrm{s} /$ he did not wish the allegation to be pursued at that time? Was it ending the abuse and implementing protective measures, even at the cost of compromising the alleged victim's relationship with the perpetrator/s and/or disruptions to his or her previous life? With the exception of cases of financial abuse, where the process of transfer of powers of attorney was well-established, the meaning of a 'good' outcome where the service user was living in their own home or with a family member was perceived to be elusive.

\section{b) The perspectives of advocates}

Compared with the ASLs, both general advocates and IMCAs seemed far more alert to what might be characterised as the person-centred aspects of safeguarding. For example, they spontaneously reported the importance of empowering alleged victims by helping them to find a 'voice', so ensuring that their experiences were at the heart of the adult safeguarding process. Not surprisingly, given this perspective, advocates emphasised the importance of engaging with service users and trying to put themselves 'in their shoes'.

\section{Focussing on a person-centred approach}

There were similarities between the ASLs' perceptions of advocates and the views expressed by advocates themselves. For example, advocates also perceived themselves to be 'independent'. They acknowledged that they had fewer constraints than ASLs on the time they were able to spend with service users, and reported that this provided greater opportunities to establish relationships with, and ascertain the wishes of, men and women who had allegedly experienced abuse. In addition, perhaps because of their more limited powers, they thought they were less likely than ASLs to be seen as threatening to service users.

However, there were also marked differences. In contrast with ASLs, for whom the setting of the alleged abuse contributed so much to their ability to adopt a personcentred approach, advocates focussed on the service user's capacity to make all the relevant decisions for themselves. They stressed, though, that the importance of capacity was merely practical because it determined whether a service user would be supported by a generic advocate or an IMCA. Capacity did not, they reported, affect their commitment to a person-centred approach. In contrast with our participant ASLs, the advocates we interviewed had very considerable experience of supporting 
service users who lived in their own homes or a family home. This was particularly the case for the IMCAs: their work primarily related to service users whose families were not considered appropriate to represent their wishes because they were the suspected perpetrators of the alleged abuse.

While acknowledging that, compared with ASLs, they had the privilege of fewer time constraints, the advocates whom we interviewed spoke at length about the complexity of their work. There were numerous challenges: for example, ascertaining the service user's wishes when these might reasonably change over time, and maintaining, as far as possible, valued relationships with family members and others. In common with ASLs, both general advocates and IMCAs reported that some kinds of alleged abuse were easier to deal with than others. Again, financial abuse was viewed as fairly straightforward: first, because there are clear and established protective measures that can be taken, and secondly, because the service user was not at immediate risk of harm. Far more challenging, from the advocates' perspective, were cases involving physical or emotional abuse, or neglect, where protecting the alleged victim from the risk of further harm could conflict with the service user's wish to remain on good terms with the perpetrator or even to continue living with him or her.

\section{Involving service users}

Consistent with their views about adopting a person-centred approach to Adult Safeguarding, both general advocates and IMCAs reported that, in order best to fulfil their role, their involvement should begin as early as possible. In particular, they felt strongly that dates for strategy meetings should not be set without first ensuring they were able to attend. Advocates told us that they would always invite their service users to strategy meetings but, interestingly, there was a consensus that the presence of service users had very little influence on outcomes. Apparently, this did not reflect any short-comings in the service: advocates told us that, when service users attended strategy meetings, ASLs made sincere efforts to both accommodate their needs and include them in the discussions. The limitations on their influence seemed, instead, to reflect the fact that there would always be a separate 'professionals' meeting', which might include the advocate, but never the service user.

\section{c) The perspectives of service users}


The three people we interviewed about their experiences of the Adult Safeguarding service, all of whom had capacity to consent to participating, comprised two men with disabilities (one with a learning disability; the other, a wheelchair user) whose former partners had been the principal perpetrators of their abuse, and an older woman who had experienced financial abuse by a support worker providing domiciliary care. All three lived in their own homes.

\section{Experiences of the Adult Safeguarding service}

The three service users spoke favourably of the ASLs, although, with one possible exception, it was difficult for them to distinguish safeguarding from broader aspects of care management. For example, the woman service user demonstrated a clear understanding of the role and responsibilities of the representative of the domiciliary agency supporting her in recruiting a new support worker; in contrast, she seemed very uncertain about these aspects of the ASL's involvement. In response to questions about their participation in Adult Safeguarding processes, all three service users reported that they had attended 'meetings', at which they were supported by, respectively, an advocate, a friend, and a family member. There had, apparently, no complaints about having been excluded or even of being included when they would rather not have been.

\section{Satisfaction with outcomes}

None of the respondents reported being entirely satisfied with the outcome of the safeguarding process. Consistent with the reports of ASLs that victims wanted the abuse to end, the service user who had been financially abused was pleased that the support worker perpetrator had been removed. The same service user also stated that she was pleased that clear guidance about the financial responsibilities and expected conduct of her new caregiver was being prepared. Unfortunately, however, she reported that she had been frightened by the safeguarding process. For reasons that we could not understand fully, but may relate to the caregiver apparently having a key to the service user's house, the ASL had moved the service user into respite care. The costs of this placement had, apparently, come from the service user's direct payment. From what we were told, the caregiver could not be dismissed immediately; instead, a process of suspension had to take place. While the service user seemed a little unsure about what had happened, she was more certain about her feelings: she had been afraid that she would not be allowed to return home. 
The service user with a learning disability was financially abused and threatened with violence by his former wife, and was fearful of both her family and his neighbours. CCTV and an alarm were installed at his home and his case had been closed to the Adult Safeguarding service. However, he reported that he did not feel safe and reported his wish for the Council to find him accommodation in another area.

The remaining interviewee in this group used a wheelchair following an accident. He had experienced a series of victimisations: financial abuse by his ex-wife, the theft of medication by one domiciliary caregiver, and medication errors by another. His home had been burgled and he had been robbed in the street. His financial affairs had now been arranged so that his former partner could no longer access his money and he had also moved to a safer neighbourhood. However, he had remaining unresolved concerns. Despite the involvement of an occupational therapist, he reported that his new home was not fully accessible, and the ramp to his front door was unsafe. He was uncertain what, if any, action was being taken against the abusive domiciliary caregivers. He had additional worries relating to his children: his former partner was impeding access, while he believed that their school was not keeping him informed about parent-teacher evenings and other events he wished to attend.

\section{Lessons from service user experiences}

These three cases highlight some of the complexities of meeting the needs of people who have, or are alleged to have, experienced abuse. Abuse is distressing and it is important that the process of Adult Safeguarding does not exacerbate service users' difficulties. For example, while it is uncertain whether or not the ASL acted proportionately in removing the woman service user from her own home, she did not appear to have received sufficient reassurance about the temporary nature of the change of her accommodation. She was also, understandably, unclear about the application of employment law in domiciliary care. The interviews with the three service users also indicated differences, which may impact on their perceptions of outcomes, between their expectations and those of the Adult Safeguarding service: for example, from an ASL's perspective, relationships with dependent children, who are not thought to be involved as perpetrators of abuse or neglect, lie outside their remit. Yet, once cases are closed, service users may still require support relating both to their experience of abuse, and for issues which, from the service's perspective, might appear to be somewhat beyond its terms of reference.

\section{Discussion}


In this study, we sought to ascertain the views of ASLs, advocates, and service users in order to evaluate how, in one county, the Adult Safeguarding service was responding to the MSP initiative. While our findings suggested genuine and sincere efforts by ASLs to involve service users in the complex and demanding process of safeguarding, they were not encouraging. Even for individuals in their own or family members' homes, ASLs' reported efforts to understand service users' experiences and feelings, ascertain their wishes about possible further actions and keep them informed of case developments appeared to be a far cry from the expectations of the MSP initiative. Indeed, in residential placements, the concept of person-centred outcomes simply seemed to make little sense; rather, the focus of ASLs was on failings in service processes and procedures, rather than any risks associated with the lives that residents had chosen or accepted. While the approach to service users living in their own homes or with their families was more person-centred, it seemed to involve a very ready, perhaps too ready, acceptance of the wishes of individuals judged to have capacity to make relevant decisions for themselves. This was the case even if the result was that alleged victims did not engage with the Adult Safeguarding service and participate in their own protection or seek redress for their abuse. In contrast with ASLs, general advocates and IMCAs worked almost entirely with men and women living in their own homes or with their families. Reflecting, perhaps, the more limited demands on their time, enabling them to establish better relationships with service users, both kinds of advocates were able to provide much more detailed accounts than ASLs of the complexity of their work, particularly in cases where individuals who had allegedly experienced physical or emotional abuse or neglect wished to continue existing relationships with their perpetrators.

The study set out to examine the efforts of ASLs, general advocates, and IMCAs to involve service users in decisions about protective measures. For ASLs, service user involvement depended, on the type of setting in which the abuse had allegedly taken place. ASLs seemed to welcome the involvement in strategy meetings of alleged victims who were living in their own homes or those of family members but it was reported that attendance was mainly restricted to younger people, with physical and/or sensory disabilities, and with perceived capacity to make relevant decisions. In contrast, both general advocates and IMCAs reported that they always sought the attendance of service users at strategy meetings, regardless of the individuals' age, disabilities, or capacity. However, the presence of users of the service was reported to have limited influence on outcomes, perhaps because they were not involved in 
the 'professionals' meetings'. It seems that influence of service users on decisions about protective measures is largely restricted to disengaging from the service.

The second objective of the study was to evaluate whether the Adult Safeguarding service was delivering outcomes valued by service users. Perhaps reflecting dissatisfaction among recipients of the service, we were able to recruit only three service users through the Council. None of these three, all of whom had been living in their own homes at the time of their first involvement with the service, seemed entirely satisfied with the outcomes of their cases. We had the impression that they were uncertain about the scope, limits and processes of the service. For at least one person, this uncertainty led to feelings of fear. The interviews with service users indicated a tension in safeguarding: what are the lengths to which a County Council might reasonably be expected to go in response to abuse? For individuals, the installation of CCTV and an alarm might appear sufficient; it would not be possible to re-house everyone who feels unsafe. Yet Councils should perhaps reflect on a decision to accommodate someone with a learning disability in a neighbourhood that is perceived by that person to be intimidating. Similarly, they might give greater consideration to their responsibilities when abusive domiciliary caregivers are supplied by a provider agency that they commission.

\section{Conclusions}

Our findings lead us to make a number of recommendations as to how this Council might make its Adult Safeguarding service more person-centred:

1. Consideration needs to be given to how 'person-centred' is defined, and how in practice it might involve more than 'service user involvement'. In particular, guidance is needed on: how best to support people to engage with safeguarding services when they are unwilling to do so and have the capacity to make the relevant decisions for themselves; the circumstances in which it might be appropriate to seek to override a service user's capacitous decision to reject support, for example by making an application to the High Court; and the interface between adult safeguarding and domestic violence. Guidance is also needed about the involvement of family members, especially, when abuse is alleged in residential settings and there are concerns about compromising the confidentiality of information about other service users. In addition, consideration should be given to the involvement of those judged to lack relevant decision-making capacity with respect to safeguarding; whether 
'professionals' meetings' are compatible with the aims of making Adult Safeguarding personal; and how best to include putatively disruptive family members in the safeguarding process.

2. With respect to Adult Safeguarding relating to alleged victims living in their own or their families' homes, consideration needs to be given as to how best they might be involved, should they remain willing to engage with the service. The demands of maintaining engagement with victims who may be distressed invites consideration of whether safeguarding inquiries should be undertaken as part of existing care management where possible, or by a member of a service specialising exclusively in safeguarding (Stevens et al., 2014). In residential settings, where abuse is generally associated with poor quality care, it may be more appropriate to address safeguarding concerns through the Council's commissioning and contracting services, rather than through a strategy meeting. Moreover, since these safeguarding cases appear to be concerned primarily with the policies and procedures of the residential services where the alleged abuse has taken place, consideration should be given to the perceived benefits of involving an IMCA in these cases if no changes of accommodation are planned.

3. The guidance to the Care Act 2014 emphasises the importance of justice and redress for men and women who have experienced abuse. In this context, consideration should be given to extending the Adult Safeguarding service's role in supporting its service users in pursuing civil and/or criminal proceedings against both individuals who have perpetrated abuse and services where abuse has taken place. At the same time, the Council should be aware of their responsibility under the Care Act to promote people's wellbeing when carrying out any of their care and support functions. Such responsibilities continue where, even after their abuse has been addressed, service users continue to experience psychological difficulties reflecting their victimisation or its consequences. Consideration also needs to be given to how Adult Safeguarding services can best challenge weak case management and poor commissioning and/or contracting decisions, particularly where there are potential conflicts of interest (Mandelstam, 2013).

4. Councils will need to consider whether decisions made in the 'best interests' of service users who lack capacity to make one or more of the relevant 
decisions for themselves but seem contrary to the person's will and preferences are person-centred. This is an issue likely to have greater significance as awareness grows of the implications of Article 12 (equality before the law) of the UN Convention on the Rights of Persons with Disabilities (United Nations, 2006).

It is very likely that these recommendations will be relevant to all English Councils. It is tempting to think that a person-centred approach provides a possible antidote to the legal and procedural intricacies of adult safeguarding. Such an idea, however, should be resisted, for while is it is essential that service users are empowered to play an active role in defining outcomes in adult safeguarding, it is also important that practitioners understand not only their own Council's policies and procedures but also the wider legal context of adult safeguarding. Only then can the well-being of adults with care and support needs be properly protected and promoted.

\section{References}

CICOUREL, A. 1964. Method and Measurement in Sociology. New York: Free Press.

DEPARTMENT OF HEALTH. 2007. Putting People First: A shared vision and commitment to the transformation of adult social care. London: Department of Health.

DEPARTMENT OF HEALTH. 2009. Safegaurding Adults: Report on the consultation on the review of 'No Secrets'. London: The Stationarey Office.

DEPARTMENT OF HEALTH. 2011. Caring for our future: Shared ambitions for care and support. London: Department of Health.

LAWSON, J., LEWIS, S., \& WILLIAMS, C. 2014. Making Safeguarding Personal 2013-14. London: Local Government Association.

MANDELSTAM, M. 2013. Safeguarding Adults and the Law, London: Jessica Kingsley.

Munby, Lord Justice (2010) 'What Price Dignity?': Keynote address at LAG Community Care conference: Protecting liberties. London, 14 July.

OGILVIE, K. \& WILLIAMS, C. 2009. Making Safeguarding Personal: A toolkit for responses. London: Local Government Association.

OGILVIE, K. \& WILLIAMS, C. 2010. Making Safeguarding Personal: a tookit for responces. London: Local Government Association.

SOCIAL CARE INSTITUTE FOR EXCELLENCE 2007. Dignity in Care: Adult servcies (Practice Guide 9). London: Social Care Intsitute for Excellence.

STEVENS, M., MANTHORPE, J., MORIARTY, J., HUSSEIN, S. \& NORRIE, C. 2014. Models of safeguarding: a study comparing specialist and nonspecialist safeguarding teams for adults [Online]. London: Kings College London. Available: http://www.kcl.ac.uk/sspp/policyinstitute/scwru/res/capacity/models.aspx [Accessed 29/09/2014 2014 ].

United Nations. 2006. Convention on the Rights of Persons with Disabilities. New York: United Nations. 